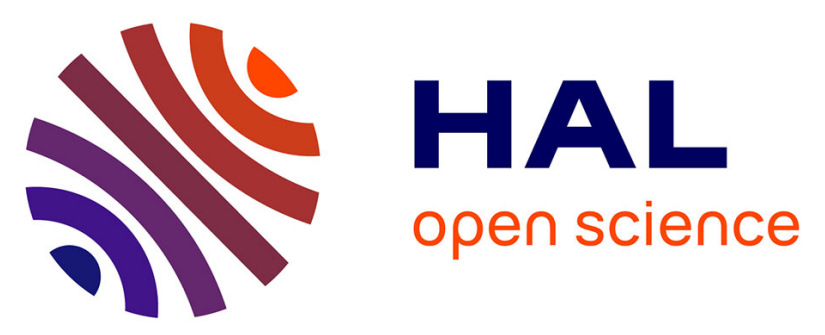

\title{
A Non-square MIMO Fractional Robust Control for the Airpath of a Diesel Engine
}

\author{
Abderrahim Lamara, Patrick Lanusse, Guillaume Colin, Alain Charlet, Yann
}

Chamaillard

\section{To cite this version:}

Abderrahim Lamara, Patrick Lanusse, Guillaume Colin, Alain Charlet, Yann Chamaillard. A Nonsquare MIMO Fractional Robust Control for the Airpath of a Diesel Engine. 2013 European Control Conference (ECC) July 17-19, 2013, Zürich, Switzerland., Jul 2013, Zurich, Switzerland. pp.3482-3487. hal-00920483

\section{HAL Id: hal-00920483 \\ https://hal.science/hal-00920483}

Submitted on 18 Dec 2013

HAL is a multi-disciplinary open access archive for the deposit and dissemination of scientific research documents, whether they are published or not. The documents may come from teaching and research institutions in France or abroad, or from public or private research centers.
L'archive ouverte pluridisciplinaire HAL, est destinée au dépôt et à la diffusion de documents scientifiques de niveau recherche, publiés ou non, émanant des établissements d'enseignement et de recherche français ou étrangers, des laboratoires publics ou privés. 


\title{
A Non-square MIMO Fractional Robust Control for the Airpath of a Diesel Engine
}

\author{
A. Lamara, P. Lanusse, G. Colin, A. Charlet, Y. Chamaillard
}

\begin{abstract}
In order to minimize pollutant emissions and more specifically nitrogen oxides, a decentralized multivariable robust control has been designed for the airpath of a Diesel engine with a turbocharger, an intake throttle and Exhaust Gas Recirculation. The control system is designed with a fractionalorder approach called CRONE (Commande Robust d'Ordre Non Entier) control, via a MIMO open-loop transfer function optimization, which maintains performance and robust stability for a wide set of operating points. The experimental results from a test-bench show the relevance of the proposed approach.
\end{abstract}

\section{INTRODUCTION}

$\mathrm{T}$ urbocharged diesel engines are widely used in transportation, especially in passenger cars due to their enhanced fuel economy. The challenge in the next European standards is to reduce nitrogen oxide $\left(\mathrm{NO}_{\mathrm{x}}\right)$ and particulate emissions. One of the classical solutions is the use of a diesel Particulate Filter and Exhaust Gas Recirculation system (EGR). In the design presented here, a throttle is added to control the air-flow entering the cylinder, which requires a more complicated control approach. The airpath control problem is treated here for a nonlinear and nonsquare system. The studied system is described in Fig. 1.1.

To avoid the generation of smoke and particulates, the airto-fuel ratio needs to be higher than the smoke limit. The tradeoff between fuel and air can be adjusted by controlling both the in-cylinder air and fuel, so relevant multivariable approaches are needed. In this work, only the airpath control is presented.

In the literature, some recent Diesel engine control studies have focused on the airpath control for NOx and smoke reduction [19].

In order to control the airflow coming through the exhaust gas recirculation, a gain-scheduled model-based feedback control of the air/ fuel ratio is presented in [3]. The authors

This project is co-financed by the European Union: Europe is committed to the region Centre with the European Regional Development Fund. A. Lamara. PHD student with IMS laboratory, CNRS UMR5218 University of Bordeaux, 351 cours de la libération, 33405 Talence, France (phone: 033(+)685905085; e-mail: abderrahil.lamara@etu.u-bordeaux1.fr) P. Lanusse. with IPB, IMS CNRS UMR5218, University of Bordeaux (phone: +33(0)540008341; e-mail: patrick.lanusse@ims-bordeaux.fr).

G. Colin. University of Orléans, PRISME, EA4229, 8 rue Léonard de Vinci, 45072 Orléans, France (phone: +33(0)238494514; e-mail: guillaume.colin@univ-orleans.fr).

A. Charlet. University of Orléans, PRISME, EA4229, (phone : +33(0)238494839; e-mail : alain.charlet@univ-orleans.fr).

Y. Chamaillard. University of Orléans, PRISME, EA4229, (phone: +33(0)238494365 ; e-mail : yann.chamaillard@univ-orleans.fr). propose two approaches involving an IMC design and a $\mathrm{H}_{\infty}$ design. A nonlinear model was first developed and then the linearized model was used to design EGR controllers.

In [1] a ninth-order model was developed using a meanvalue engine model approach. Singular value decomposition was then used to identify the effective range of the plant. Finally a gain-scheduled multivariable controller with two integrators was designed by applying the LQG control design methodology.

A nonlinear predictive control based on local networks for air management in diesel engines was discussed in [4]. In [6] the authors demonstrate the relevance of motion planning in the control of the airpath with EGR.

Most of the research presented above uses a mean-value engine model to design a controller, which requires long test periods. In [2] a fuzzy controller was proposed, without using a physical model.

In this study, a frequency-domain system-identification method is used to define the nominal plant. The frequency data are used for system-control design.

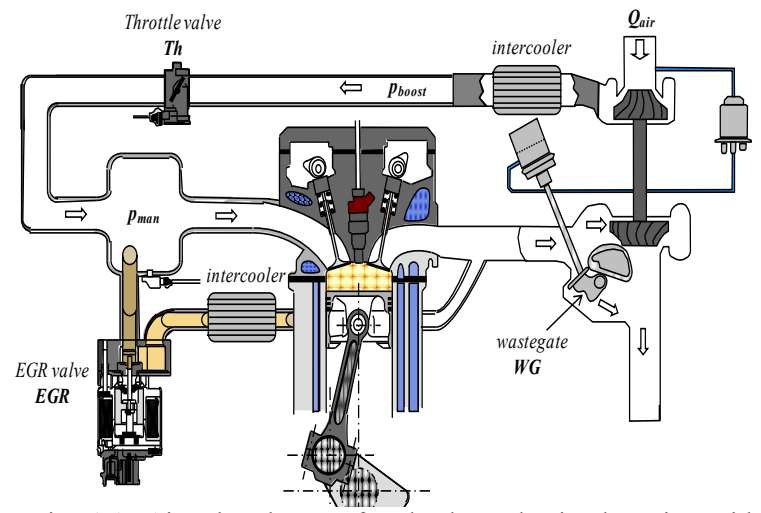

Fig. 1.1. Airpath scheme of turbocharged Diesel engine with throttle and exhaust gas recirculation (EGR).

Our work is based on [5], where the CRONE approach was used to design a MIMO controller to control a square system, with two inputs and two outputs $(2 \times 2)$. The main contribution of the present paper is to extend the CRONE approach to a non-square system, with three inputs and two outputs (3x2). Here the system is not split in two areas. Only one controller is used to control the airpath around all operating points, by acting simultaneously on the three actuators.

The paper is organized as follows. After a description of the system in section II, section III presents the multisine system identification. In section IV the CRONE approach is explained 
. The decentralized controller is assessed in section V. Test bench results are presented and discussed in the last section.

\section{SYSTEM DESCRIPTION}

The system to be controlled is the airpath of a turbocharged Diesel engine with 4 cylinders, 2.0L and a power of $81 \mathrm{~kW}$. The fresh air (mass flow $Q_{\text {air }}$ ) coming from the atmosphere is compressed and warmed up by the compressor. The exchanger cools it down, thus increasing the density and decreasing the boost pressure ( $\left.\mathrm{p}_{\text {boost }}\right)$. The throttle valve (Th) controls the $Q_{a i r}$ which enters the intake manifold. After combustion, burned gases (so $Q_{\text {air }}$ ) can be recirculated into the intake manifold through the EGR valve and cooled down by the EGR intercooler. EGR decreases the mean combustion temperature and reduces $\mathrm{NO}_{\mathrm{x}}$ production, but decreases engine efficiency (max torque). The exhaust flow also enters the turbine and speeds it up. This turbine energy is transmitted to the compressor through a shaft. The turbine speed ( $\left.\mathrm{p}_{\text {boost }}\right)$ is adjusted by the wastegate $(W G)$ position.

Two sensors will be used to control the airpath: boost pressure $\mathrm{p}_{\text {boost }}$ and air-flow $Q_{\text {air }}$ coming through the throttle.

\section{SYSTEM IDENTIFICATION}

A multisine excitation signal is used here to identify the airpath system. The use of this broadband signal allows faster frequency domain identification. The system identification of the airpath system is made around all (73) operating points (blue points in Fig. 2.1)

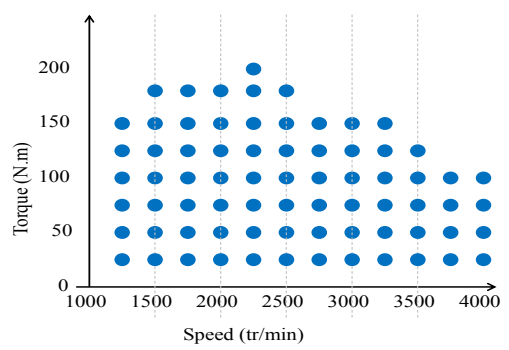

Fig. 2.1. Points used for system -identification.

The identification step requires multisine signal specifications. This signal is a linear combination of cosines which is given by:

$$
u(t)=u_{0}+A_{0} \sum_{k=1}^{N} A_{k} \cos \left(2 \pi f_{k} t+\varphi_{k}\right)
$$

where $N$ is the number of harmonics in the signal, $f_{k}$ is a harmonic frequency, $A_{k}$ is the harmonic amplitude, and $\varphi_{k}$ is the initial phase of each harmonic.

The amplitude $A_{0}$ is chosen in such a way that the system remains at the same operating point during identification, and also gives a linear response. Frequencies $f_{k}$ are chosen such that the time-invariant nominal model approximates the most important linear dynamics of the real system. The max frequency $f_{N}$ should be greater than the desired cut-off frequency of the system.
The identification of each element of the transfer matrix consists in exciting only one input, each mean value of the three inputs ensuring the chosen operating point. Then each element of the matrix is calculated using the fast Fourier transform (FFT) of the ratio of the cross-correlation between output and input $\tau_{y x}$ divided by the autocorrelation of the input $\tau_{x x}$ :

$$
G=\frac{F F T\left(\tau_{y x}(\text { output, input })\right)}{F F T\left(\tau_{x x}(\text { input })\right)}
$$

Each input-output transfer function is then described:

$$
\begin{aligned}
& \boldsymbol{G}_{\mathbf{1 1}} \text { : from } E G R(\%) \text { to } Q_{\text {air }}(\mathrm{g} / \mathrm{s}) \\
& \boldsymbol{G}_{\mathbf{1 2}} \text { : from } T h(\%) \text { to } Q_{\text {air }}(\mathrm{g} / \mathrm{s}) \\
& \boldsymbol{G}_{\mathbf{1 3}} \text { : from } W G(\%) \text { to } Q_{\text {air }}(\mathrm{g} / \mathrm{s}) \\
& \boldsymbol{G}_{\mathbf{2 1}} \text { : from } E G R(\%) \text { to } P_{\text {boost }}(\mathrm{bar}) \\
& \boldsymbol{G}_{\mathbf{2 2}} \text { : from } T h(\%) \text { to } P_{\text {boost }} \text { (bar) } \\
& \boldsymbol{G}_{\mathbf{2} 3} \text { : from } W G(\%) \text { to } P_{\text {boost }} \text { (bar) }
\end{aligned}
$$

The signal excitation is chosen with a sampling frequency at $1 \mathrm{kHz}$, a frequency range from 0.1 to $1 \mathrm{~Hz}$ and contains 10 frequencies. Fig. 2.2 presents the Bode diagram computed from (2). For the FFT calculus, a triangular window is used to reduce the noise effect.

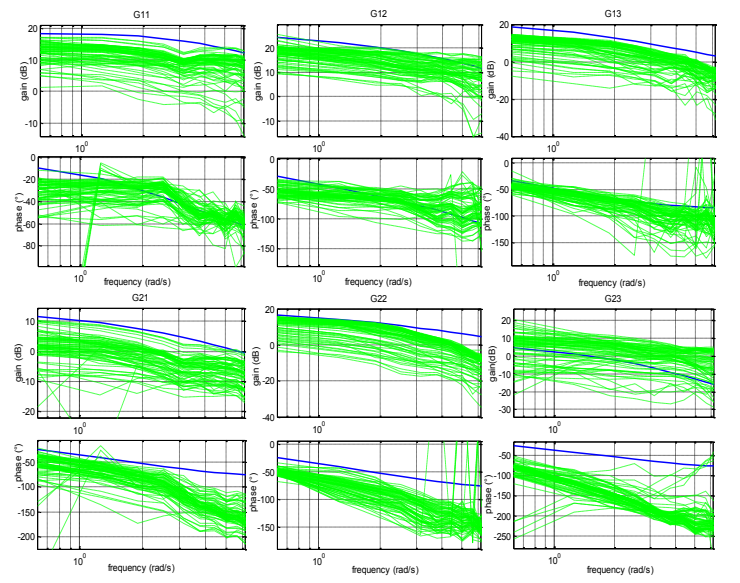

Fig. 2.2. Bode diagram of nominal plant frequency response (solid blue curves) and all operating point frequency responses (green dashed curves).

As shown on Fig. 2.2, an arbitrary nominal plant without a delay element is defined with max gain min phase criteria. Its function transfer matrix expression is given by:

$$
\left[\begin{array}{ccc}
-\frac{29(s+1.03)}{\left(s^{2}+4.4 s+3.58\right)} & -\frac{255(s+2.59)}{\left(s^{3}+12.5 s^{2}+44.7 s+34.3\right)} & \frac{8.7(s+2.88)}{\left(s^{2}+3.45 s+2.5\right)} \\
-\frac{6(s+1.3)}{\left(s^{2}+2.86 s+1.86\right)} & -\frac{11.2(s+2.28)}{\left(s^{2}+4.3 s+3.3\right)} & \frac{7(s+2.1)}{\left(s^{3}+6.6 s^{2}+13 s+7.2\right)}
\end{array}\right]
$$

\section{MIMO CRONE DESIGN METHODOLOGY}

The CRONE control-system design methodology is a frequency-domain approach that has been used since the eighties [7] [9] [10] [11]. The system-control is based on a unity-feedback configuration (Fig. 4.1).

The objective of the CRONE control system design is to robustify the closed-loop dynamic performance through either a robust damping factor, or a robust resonant peak.

The aim of the CRONE MIMO design is to find a nominal diagonal closed-loop transfer matrix between setpoints and 
outputs. The nominal open-loop transfer matrix being defined by

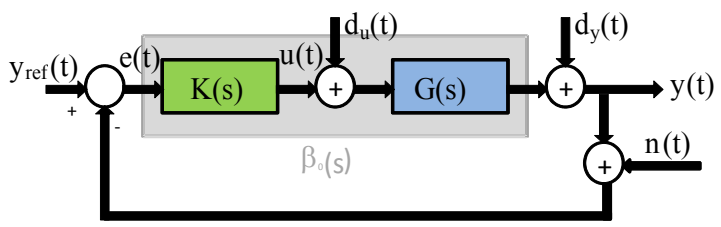

Fig. 4.1. Unity-feedback configuration for CRONE approach.

$$
\beta_{0}=G_{0}(s) K(s)
$$

for non-square systems [12] [13], the optimization of $\beta_{0}$ makes it possible to calculate the controller using:

$$
K(s)=G_{0}^{\dagger}(s) \beta_{0}(s)
$$

where $G_{0}^{\dagger}(s)$ is the Moore-Penrose pseudo-inverse of nominal plant $G_{0}(s)$.

Using Graybill's theorem [14] the matrix $A_{0}^{\dagger}$ of rank $r$ can be calculated as:

$$
\begin{aligned}
& \forall m>n \Rightarrow \exists A^{\dagger}=A^{H} \cdot\left(A A^{H}\right)^{-1} \text { with } A A^{\dagger}=I_{n x m} \\
& \forall n>m \Rightarrow A^{\dagger}=\left(A A^{H}\right)^{-1} \cdot A^{H} \text { with } A^{\dagger} A=I_{n x m} \\
& \text { where } A^{H} \text { is the Hermitian transpose of } A .
\end{aligned}
$$

$$
\text { Let } G_{0}(s)=\left[\begin{array}{l}
g_{11}(s) \ldots g_{1 n}(s) \\
g_{m 1}(s) \ldots g_{m n}(s)
\end{array}\right]
$$

and $g_{i j}(s)=h_{i j}(s) e^{-L_{i j} s}$

- $h_{i j}(s)$ : is a strictly proper time-delay free transfer function,

$$
\text { - } L_{i j} \in \mathfrak{R}^{*_{+}} \text {. }
$$

Then

$$
G_{0}^{\dagger}=P(s)=\left[\begin{array}{l}
p_{11}(s) e^{y_{11}(s)} \ldots p_{1 n}(s) e^{y_{1 n}(s)} \\
p_{m 1}(s) e^{y_{m 1}(s)} \ldots p_{m n}(s) e^{y_{m n}(s)}
\end{array}\right]
$$

where $P(s)$ is the non-zero polynomial of $s$ with timedelay, and $y_{i j} \in \mathfrak{R}^{*+}$.

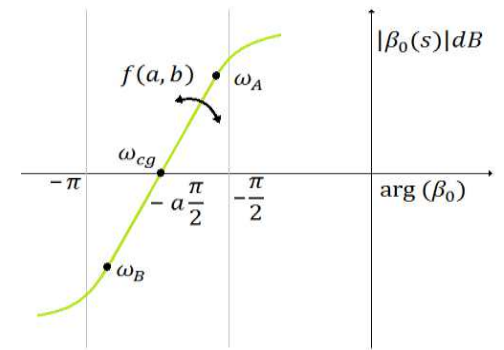

Fig. 4.2: Generalized template in the Nichols chart.

Each element of the nominal diagonal open-loop matrix is based on the third generation CRONE single-input singleoutput (SISO) methodology. The principle of this methodology is to optimize the parameters of a nominal open-loop transfer function $\beta_{0}(s)$ that includes a bandlimited complex fractional order integration over a frequency range $\left[\omega_{A}, \omega_{B}\right]$. The complex fractional order, $n=$ $a+\mathrm{i} b$ makes loop-shaping easier by enabling a straight line of any direction to be created in the Nichols chart which is called the generalized template (Fig. 4.2).

The SISO nominal open-loop transfer function is defined by:

$$
\beta_{0}=\beta_{l}(s) \beta_{m}(s) \beta_{h}(s)
$$

- where $\beta_{m}(s)$ is a set of band-limited generalized templates:

$$
\beta_{m}(s)=\prod_{k=-N^{-}}^{N} \beta_{m k}(s)
$$

with:

$$
\begin{gathered}
\beta_{m}(s)=C_{k}^{\operatorname{sign}\left(b_{k}\right)}\left(a_{k} \frac{1+\frac{s}{\omega_{k+1}}}{1+\frac{s}{\omega_{k}}}\right)^{a}\left(\Re_{/ i}\left(\left[a_{k} \frac{1+\frac{s}{\omega_{k+1}}}{1+\frac{s}{\omega_{k}}}\right)^{i b}\right)^{-q \operatorname{sign}\left(b_{k}\right)}\right. \\
a_{k}=\left(\frac{\omega_{k+1}}{\omega_{k}}\right)^{\frac{1}{2}} \text { for } k \neq 0 \text { and } a_{0}=\left(\frac{1+\left(\frac{\omega_{\mathbf{r}}}{\omega_{\mathbf{O}}}\right)^{2}}{1+\left(\frac{\omega_{\mathbf{r}}}{\omega_{1}}\right)^{2}}\right)^{\frac{1}{2}}
\end{gathered}
$$

where $\beta_{l}(s)$ is an integer order $n_{l}$ proportional integrator

$$
\beta_{l}(s)=C_{l}\left(\frac{\omega_{-N^{-}}}{s}+1\right)^{n_{l}}
$$

- where $\beta_{h}(s)$ is the low-pass filter of integer $n_{h}$

$$
\beta_{h}(s)=C_{h}\left(\frac{s}{\omega_{N^{+}}}+1\right)^{n_{h}}
$$

Gains $C_{k}, C_{l}$ and $C_{h}$ are such that $\omega_{\mathrm{r}}$ is the closed-loop resonant frequency. Order $n_{l}$ has to be set to manage the accuracy provided by the control-system. Order $n_{h}$ has to be set to obtain a proper or bi-proper control-system. When useful, $N^{-}$and $N^{+}$are different from 0 to increase the number of tuning parameters used for open-loop shaping.

For time-delay, non-minimum phase or unstable SISO systems, the SISO open-loop transfer function must include the nominal time-delay and right half plane zeros and poles of $G_{0}$ to make the controller achievable and the closed loop fully stable [10] [11].

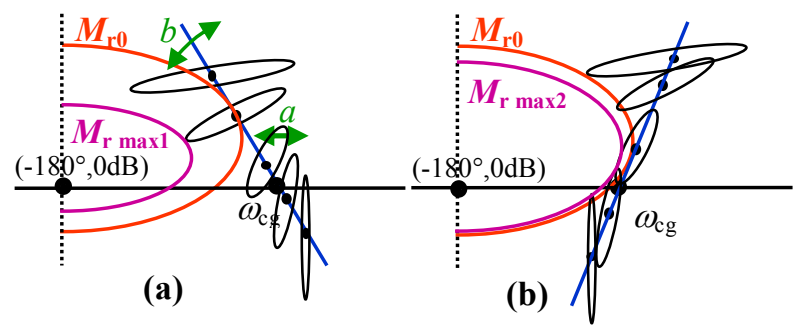

Fig. 4.3: (a) any generalized template and (b) optimal template 
Fig. 4.3 shows that the optimal approach allowed by the generalized template ensures an optimal positioning of the frequency uncertainty domains which reduce the resonant peak $M_{\mathrm{r}}$ variations (strongly correlated to overshoot variations) of the complementary sensitivity function $T(s)$ : $M_{\mathrm{r} \max 2}$ is closer to $M_{\mathrm{r} 0}$ than $M_{\mathrm{r} \max 1}$ is.

The robustness cost function which is minimized is given by:

$$
J=\left(M_{r_{0}}-\inf \left|M_{r}\right|\right)^{2}+\left(\sup \left|M_{r}\right|-M_{r_{0}}\right)^{2}
$$

where $M_{r_{0}}$ is a chosen nominal value of the resonant peak. Its minimization is accomplished while respecting closedloop constraints for all plants $G$ and for $\omega \in \mathfrak{R}^{+}$:

$$
\begin{aligned}
& \inf |T(j \omega)| \geq T_{1}(\omega), \sup |T(j \omega)| \leq T_{u}(\omega), \\
& \sup |S(j \omega)| \leq S_{u}(\omega), \sup |K S(j \omega)| \leq K S_{u}(\omega) \\
& \sup |G S(j \omega)| \leq G S(\omega)
\end{aligned}
$$

where

$$
\left\{\begin{array}{l}
T(s)=\frac{G(s) K(s)}{1+G(s) K(s)}, S(s)=\frac{1}{1+G(s) K(s)} \\
K S(s)=\frac{K(s)}{1+G(s) K(s)}, G S(s)=\frac{G(s)}{1+G(s) K(s)}
\end{array}\right.
$$

The frequency uncertainty domains are defined from the multiplicative uncertainty of the open-loop frequency response in the Nichols chart. This multiplicative uncertainty is invariant and equal to the plant uncertainty:

$$
\beta(s)=G(s) K(s)=G_{0}(s) \Delta_{m} K(s)=\beta_{0}(s) \Delta_{m}
$$

where $G_{0}$ and $\beta_{0}$ are the nominal plant and open-loop transfer function, and where $\Delta_{m}$ is a multiplicative uncertainty model.

For MIMO systems, the resonant peaks taken into account by the cost function to be minimized are those of the diagonal elements of the perturbed values (as for SISO systems, not only the nominal one) of the complementary sensitivity transfer function matrix and the controller elements are obtained from relations (5) and (7):

$$
K_{i j}(j \omega)=P_{i j}(j \omega) e^{y_{i j}(j \omega)} \beta_{j j}(j \omega)
$$

To ensure the system stability, the nominal open-loop transfer function should include some time-delays and poles and zeros in the right half-plane and lightly damped modes which appear in $P(s)$ [8][13] . As $\beta_{j j}(s)$ are fractional order transfer functions, the rational transfer functions $K_{\mathrm{Rij}}(s)$ are obtained by identifying the ideal frequency responses $K_{i j}(\mathrm{j} \omega)$ by low-order transfer functions:

$$
K_{\mathrm{R}_{i j}}(s)=\frac{B(s)}{A(s)}
$$

where $B(s)$ and $A(s)$ are polynomials of specified integer degrees $n_{\mathrm{B}}$ and $n_{\mathrm{A}}$. All the frequency-domain systemidentification techniques can be used [15] [16]. Whatever the complexity of the control problem, it is easy to find satisfactory values of $n_{\mathrm{B}}$ and $n_{\mathrm{A}}$ generally about 6 without a reduction in performance.

\section{DESIGN OF A DECENTRALIZED CRONE CONTROLLER}

For non-square systems, the Block Relative Gain (BRG) array method [17] [18] is used to evaluate different block interactions. A system is weakly interacting if the BRG array is close to the identity matrix. If the singular values of the BRG are very different from unity, the closed-loop system has large interactions. Thus the BRG method can be used to allocate inputs to outputs. Then to simplify the use of the proposed MIMO methodology and to obtain a block decentralized controller, all the blocks with a weak BRG index are assumed equal to zero. In our study we assume an arbitrary simplified new nominal plant $G_{0}^{\prime}$ defined by:

$$
G_{0}^{\prime}=\left[\begin{array}{ccc}
G_{11} & G_{12} & 0 \\
0 & 0 & G_{23}
\end{array}\right]
$$

Using (5) and this new nominal plant lead to one decentralized controller per block. Although it is designed using a MIMO approach, such a controller makes it possible to control one of the outputs even if the other one cannot be measured (sensor loss). Fig. 5.1 shows the decentralized control-system proposed for the MIMO airpath system.

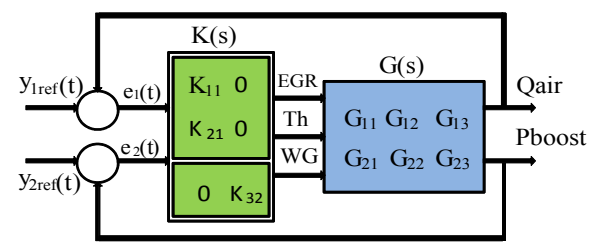

Fig. 5.1: Decentralized control of a $3 \times 2$ MIMO plant.

However, the elements of the nominal (and diagonal) open loop transfer function matrix are optimized by taking into account the full MIMO transfer function frequency response defined by $G$ (Fig. 2.2). Referring to previous experiments, the identification frequency range is limited to $1 \mathrm{~Hz}$ because of the noise effect. This limitation could prevent good optimization of the open-loop frequency response and makes it mandatory to ensure a sufficient controller roll-off. For this reason, the non band-limited defined nominal plant is also used for the open-loop optimization and noise rejection.

Fig. 5.2 presents the optimized nominal open-loop frequency responses (red). The multiplicative uncertainty (green) resulting from all the perturbed equivalent open-loop frequency responses has been placed as far as possible outside the low stability area of the Nichols chart. For the open-loop optimization of $\beta_{1}(s)$, a resonance frequency about $4.5 \mathrm{rad} / \mathrm{s}$ and a bandwidth of $6 \mathrm{rad} / \mathrm{s}$ were chosen. For $\beta_{2}(s)$ a resonance frequency about $2.1 \mathrm{rad} / \mathrm{s}$ and a bandwidth of $3.2 \mathrm{rad} / \mathrm{s}$ were chosen.

Fig. 5.3 and Fig. 5.4 present the closed loop sensitivity functions $T(s)$ and $K S(s)$. From the complementary sensitivity function $T_{21}$, we can note that at $4.5 \mathrm{rad} / \mathrm{s}$, each 1 mbar could generate a noise of $0.3 \mathrm{~g} / \mathrm{s}$ at the airflow output. Also from $T_{12}$ at $2 \mathrm{rad} / \mathrm{s}, 1 \mathrm{~g} / \mathrm{s}$ could generate a noise of 10 mbar at the boost pressure output. So $Q_{\text {air }}$ could be more affected by $p_{\text {boost }}$ pressure than $p_{\text {boost }}$ by $Q_{\text {air }}$. 

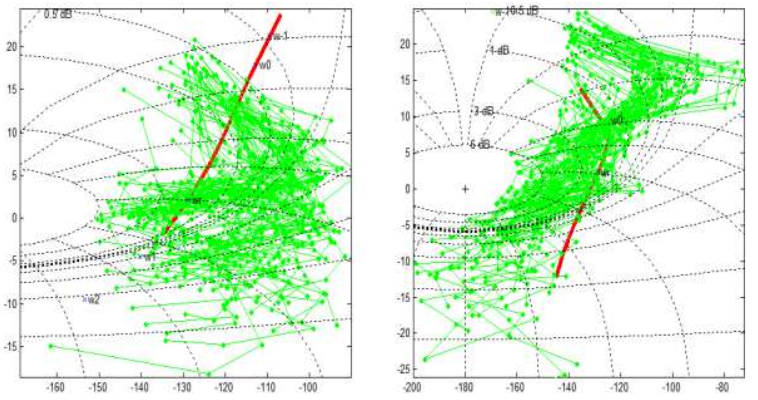

Fig. 5.2: Optimization of open-loop in the Nichols chart, $\beta_{1}(s)$ for air flow control (left) and $\beta_{2}(s)$ for boost pressure control (right).
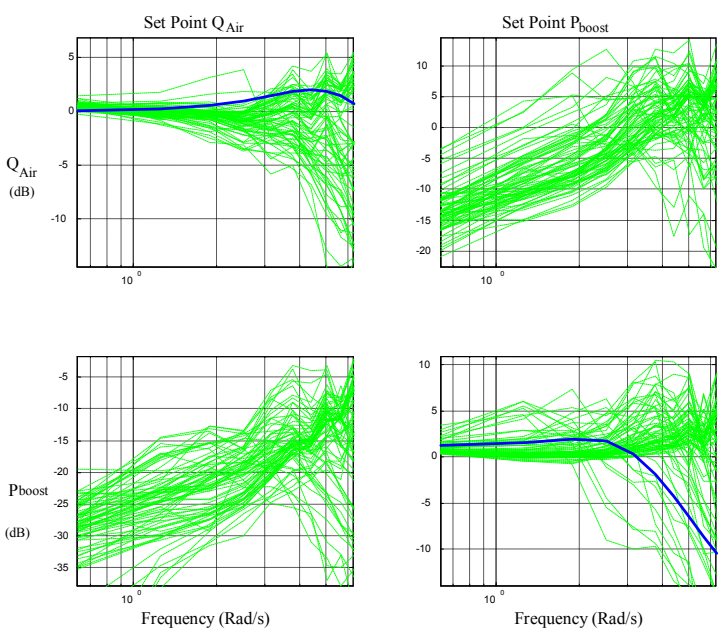

Fig. 5.3: Complementary sensitivity function $T(s)$.

As explained previously, low order rational transfer functions are used to approximate the desired frequency response of each element of the decentralized controller:

$$
\begin{aligned}
& K_{11}(s)=-\frac{42\left(s^{2}+11.3 s+39\right)}{s^{4}+65.7 s^{3}+1210 s^{2}+6000 s+5929} \frac{s+1.15}{s} \\
& K_{21}(s)=\frac{9.6\left(s^{2}+13 s+51\right)}{s^{3}+57 s^{2}+844 s+1308} \frac{s+0.77}{s} \\
& K_{31}(s)=\frac{256\left(s^{6}+42 s^{5}+670 s^{4}+4314 s^{3}+1.16 e 4 s^{2}+1.27 e 4 s+5766\right)}{s^{7}+112 s^{6}+4968 s^{5}+9.6 e 4 s^{4}+6.4 e 4 s^{3}+1.5 e 6 s^{2}+1.3 e 6 s+2.6 e 5} \frac{s+0.7}{s}
\end{aligned}
$$

An anti-windup system has been added to these three elements for the implementation: the integral parts have been fed back using actuator saturation models [5].
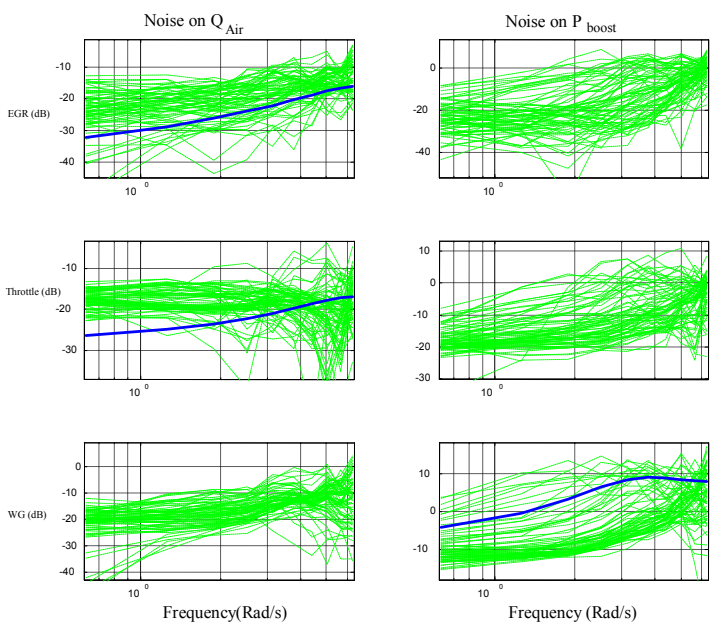

Fig. 5.4: Sensitivity function $K S(s)$

\section{EXPERIMENTAL RESULTS}

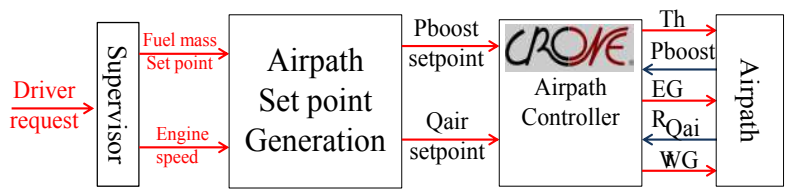

Fig. 6.1: Implementation of the controller.

Fig. 6.1 shows how the airpath controller has been implemented. From the driver request, $\mathrm{p}_{\text {boost }}$ and $Q_{\text {air }}$ setpoints are defined using static maps.
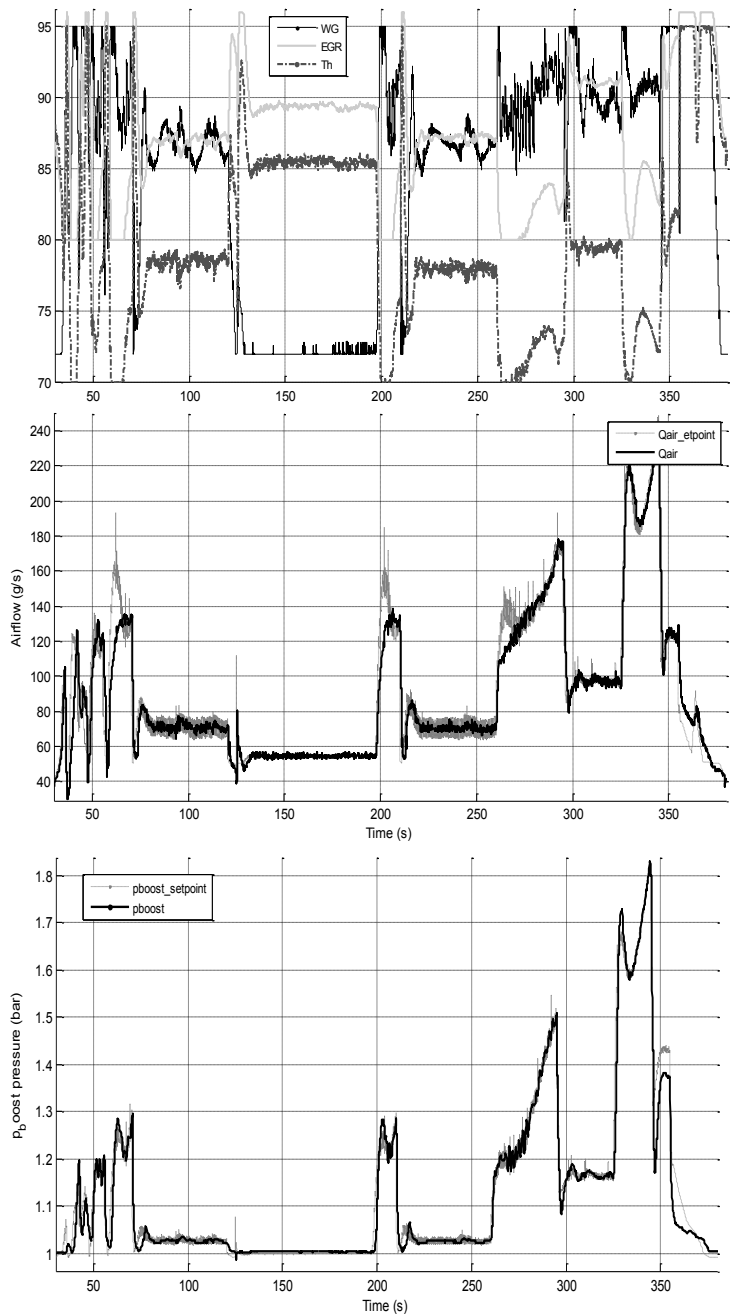

Fig.6.2: $W G, E G R$ and Th control efforts (up top graph, in \%), $Q_{\text {air }}$ tracking (middle centre, in $\mathrm{g} / \mathrm{s}$ ) and $p_{\text {boost }}$ tracking (down bottom, in bar) versus time (s).

Fig. 6.2 shows the $\mathrm{p}_{\text {boost }}$ and $Q_{\text {air }}$ tracking during a NEDC extra-urban test cycle. In this kind of test, most of the engine operating points stay in the pollutant area.

Analyzing the commands sent to the actuators in order to reach the setpoints, one notes a time delay of about $0.5 \mathrm{~s}$ in idle speed and about $0.2 \mathrm{~s}$ in low speed. Despite the speed variation, the non-square controller proves its ability in setpoint tracking and ensures robustness during changes in the operating points. No significant overshoot and no static error are observed.

At $260 \mathrm{~s}, Q_{\text {air }}$ cannot reach the setpoint due to the 
saturation of the valves. Thanks to the decentralized controller, p poost reaches its setpoint. How can one loop continue to operate even though one sensor has been lost? The system can therefore be tested with a single sensor. .

The EGR valve saturation is fixed here at $80 \%$ in order to avoid flow circulation from intake to exhaust, and hence to avoid critical engine behavior variation.

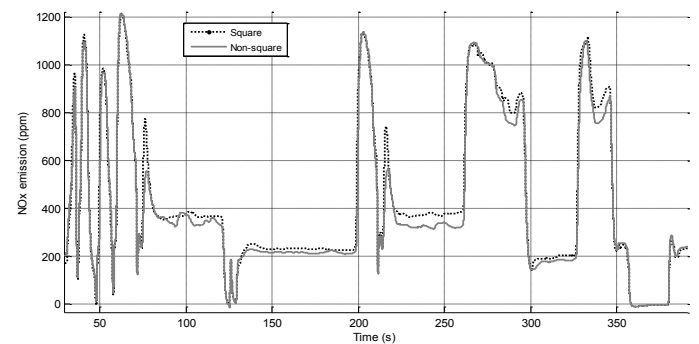

Fig.6.3: Comparison between NOx emissions of a square and nonsquare controller.

Fig. 6.3 compares the NOx emissions of a non-square $(3 \times 2)$ and a square $(2 \times 2)$ controller during the NEDC test cycle. It can be seen that the NOx emissions with a nonsquare controller are less than with the square controller especially in transitions. This difference is due to the throttle valve, which adjusts the air-flow entering the intake more rapidly.

In [20] the proposed system control was compared with an industrial solution in simulation.

\section{CONCLUSION}

The paper has proposed a frequency-domain method to design a robust non-square $(2 \times 3)$ control system. This control system was used here to control the airpath of a turbocharged diesel engine. After frequency-domain system identification, a decentralized ( $3 \times 2)$ CRONE control system was designed by optimizing open-loop behaviors, while ensuring good frequency-domain closed-loop specifications. The control performance of the proposed method was demonstrated on a NEDC cycle experimental test. NOx emission was evaluated to check the pollutants reduction.

The CRONE controlsystem for a (3x2) system with throttle ensures robustness on setpoint tracking and $\mathrm{NOx}$ reduction.

\section{REFERENCES}

[1] A.G. Stefanopoulou, I.Kolmanovsky, and J.S. Freudenberg Control of variable geometry turbocharged diesel engines for reduced emissions. IEEE Transaction on control systems technology, vol. 8, $\mathrm{n}^{\circ}$. 4, July 2000.

[2] J.F. Arnold, N Langlois, and H. Chafouk. Fuzzy controller of the airpath system of a diesel engine: Real time simulation. European Journal of Operational Research vol 193, $\mathrm{n}^{\circ} 1$, pp 282-288, February 2009

[3] E. Alfieri, A. Amstutz, and L. Guzzella Gain Scheduled model-based feedback control of the air/fuel ratio in diesel engine. Control Engineering Practice. vol 17, n 12 , pp 1417-1425, December 2009.

[4] S. Garcia-Nieto, M. Martinez, X. Blasco, and J. Sanchis Nonlinear predictive control based on local model networks for air management in diesel engines. Control Engineering Practice, vol 16, $\mathrm{n}^{\circ} 12$, pp 1399-1413, December 2008.

[5] G. Colin, P. Lanusse, A. Louizimi, Y. Chamaillard, C. Deng, and D. Nelson-Gruel Multi-SISO robust CRONE design for the airpath control of s diesel engine. IFAC Milano, August 28,2011

[6] J. Chauvin, A. Alberecht, G. Corde, and N. Petit Modeling and control of a diesel HCCI engine, IFAC AAC 2007.

[7] A. Oustaloup, Systèmes asservis linéaires d'ordre fractionnaire. Masson, Paris, 1983.

[8] D. Nelson Gruel, V. Pommier P, Lanusse, and A. Oustaloup, Robust control system design for multivariable plants with lightly damped modes, IDETC/CIE, Las Vegas. Nevada, USA 2007.

[9] A. Oustaloup, B. Mathieu, P. Lanusse, The CRONE control of resonant plants: application to a flexible transmission. European Journal of Control, vol. 1, n², pp. 113-121, 1995.

[10] P. Lanusse, De la commande CRONE de première génération à la commande CRONE de troisième generation. PhD Thesis, Bordeaux I University, France, 1994.

[11] P. Lanusse, A Oustaloup, Control of time-delay systems using robust fractional-order control and robust smith predictor based control. ASME International Design Engineering Technical Conferences and Computers and Information in Engineering Conference, Long Beach, California, 2005.

[12] D. Nelson Gruel, P. Lanusse, and A. Oustaloup, Decentralized CRONE control of mxn multivariable system with time-delay. 3rd IFAC Workshop on "Fractional Differentiation and its Applications", Ankara, Turkey, 2008.

[13] D. Nelson Gruel, P, Lanusse, and A. Oustaloup, Robust control design for multivariable plants with time-delays. Chemical Engineering Journal - Elsevier, vol. 146, Issue 3, pp 414-427, 2009.

[14] F.A. Graybill, Introduction to matrices with applications in statistics, Wadsworth, 1969.

[15] A. Oustaloup, P. Melchior, P. Lanusse, O. Cois, and F. Dancla, The CRONE toolbox for Matlab. IEEE International Symposium on Computer-Aided Control System Design, Anchorage, Alaska, 2000.

[16] A. Oustaloup, P. Lanusse, and F. Levron, Frequency synthesis of filter using the functions of viète's roots. IEEE Transactions on Automatic Control, vol. 47, n5, pp. 837-841, 2002.

[17] J. B. Hoagg, S. L. Lacy, V. Babuska, and S. Bernstein Sequential multisine signals for system identification of large space structures, Proceedings of the American Control Conference, Minneapolis, Minnesota, USA June 2006.

[18] V. Kariwala, J. Fraser Forbes, and E. S. Meadows Block relative gain: properties and pairing rules. Ind. Eng. Chem. Res., 42 (20), pp 4564 4574, 2003.

[19] F. Tschanz, A. Amstutz, C. H. Onder, L. Guzzella Feedback control of particulate and nitrogen oxide emission in diesel engines Control. Engineering Practice October 2012.

[20] A. Lamara, G. Colin, P. Lanusse, Y. Chamaillard, A. Charlet, Decentralized robust control-system for a non-square MIMO system, the air-path of a turbocharged Diesel engine. IFAC workshop ECOSM 20 December 2012 Rueil-Malmaison France. 